\title{
Evaluation of wound healing treated with latex derived from rubber trees and Aloe Vera extract in rats ${ }^{1}$
}

\author{
Marcelo Luiz BrandãoI, Paulo Roberto Melo Reis ${ }^{\mathrm{II}}$, Lilhian Alves de Araújo ${ }^{\mathrm{III}}$, Ana Carolina Vicente Araújo ${ }^{\mathrm{IV}}$, Maisa Helena de \\ Abreu Silva Santos ${ }^{\mathrm{IV}}$, Marina Pacheco Miguel $^{\mathrm{V}}$
}

DOI: http://dx.doi.org/10.1590/S0102-865020160090000001

${ }^{\mathrm{P} h D}$, Associate Professor, Laboratory of Surgical Technique, School of Medical Sciences, Pharmaceutical and Biomedical, Pontificia Universidade Católica de Goiás (PUC-Goiás), Goiania-GO, Brazil. Intellectual, scientific and design of the study; acquisition and interpretation of data; technical procedures; critical revision; supervised all phases of the study.

"PhD, Associate Professor, Master's Program in Environmental Sciences and Health, School of Medical Sciences, Pharmaceutical and Biomedical, PUC-Goiás, Goiania-GO, Brazil. Intellectual, scientific and design of the study; acquisition and interpretation of data; technical procedures; critical revision.

${ }^{\mathrm{II}}$ Master, Fellow PhD degree, Program in Biotechnology and Biodiversity - Pro-Midwest Network, Universidade Federal de Goiás (UFG), GoianiaGO, Brazil. Acquisition of data, technical procedures.

${ }^{\mathrm{IV}}$ Graduate student, School of Medical Sciences, Pharmaceutical and Biomedical, PUC-Goiás, Goiania-GO, Brazil. Acquisition, analysis and interpretation of data; statistical analysis; technical procedures; manuscript preparation.

${ }^{v} \mathrm{PhD}$, Class A Professor, General Pathology, Tropical Institute of Pathology and Public Health, UFG, Goiania-GO, Brazil. Technical procedures, analysis and interpretation of data, statistical analysis, manuscript preparation, critical revision.

\section{ABSTRACT}

PURPOSE: To compare the use of latex derivative and Aloe vera extract to wound healing.

METHODS: Twenty one rats were randomly divided into three groups and each one had a wound made by incision. The treatment consisted in: derivative of latex (GL), Aloe vera extract (GA) and saline solution (GC). The wound area was measured on the 7th, 14th and 21 st days and macroscopic and microscopic evaluation were done.

RESULTS: The comparison between the measurements of the wounds presented statistical difference in GC and GA from the 7th day of evaluation and GL from the 14th day. The extent of the wound was significantly smaller by the 7th day in GL. Histologically, in GL, the neovascularization was significant on the 7th, 14th and 21 st days. On the 21 st day the scar was large and little mature. In GA and GC, the findings were similar on the 7th, 14th and 21st days with a slight better organization of skin and collagen on the 21 st in GA.

CONCLUSIONS: Statistical analysis did not allow for the definition of the best topical agent. The latex had the highest angiogenesis, but a possible foreign body granuloma. Aloe vera has revealed a healing process adequated temporally in histology.

Key words: Angiogenesis. Wound Healing. Aloe. Hevea. Rats. 


\section{Introduction}

Tissue repairing is a complex, dynamic and systemic process which depends on favorable environmental conditions, especially during topical therapy. In most cases, complications may occur during the healing process in its inflammatory phase by secondary bacterial contamination, imbalance of reactive metabolites and lack of satisfactory vascularization, which depends on the local conditions of the wound, the general condition of the patient and the presence of associated systemic diseases ${ }^{1}$.

Dressing is a treatment form for cutaneous wounds and choosing one depends on intrinsic and extrinsic factors. There is a wide range of manufactured and natural products in the market, and this study was chosen to compare the serum of Hevea brasiliensis and the extract of Aloe vera.

It was demonstrated biocompatibility and endotelial growth of the latex in a study with the use of vascular fabric and drilled latex prostheses into arteries of $\operatorname{dogs}^{2}$. Another study used the latex membrane with $0.1 \%$ of polylysine in the perineal herniorrhaphy of dogs allowing the occlusion of the hernial ring with granulation during tissue formation and subsequent membrane removal. In man, the latex membrane was used in the treatment of ischemic leg ulcers and it was considered an important agent of cicatricial tissue inducer and tissue remodeling. It was effectively used in relapsing umbilical hernioplasty in cattle.

The right actuation mechanism of latex in the cicatricial process is still not known yet, but it is believed that its satisfactory performance is due to its participation in the angiogenesis activation $^{3}$, which motivates new studies in this area.

Babosa, most commonly known as Aloe vera, contains a gel in its parenchyma which the main cicatricial substract is the mannose- 6 phosphate, proliferative stimulant for fibroblasts, macrophages and angiogenesis ${ }^{4}$, besides containing the anthraquinone known as antibacterial, antiviral and antifungal components. It was cited in several experimental works and it has been used in traditional medicine ${ }^{5}$.

Aloe vera has been used for burn healing, wound healing, pain relief, besides being a powerful moisturizing agent. A study showing its use in chronic anal fissures presented benefits on the clinical condition of patients and reports of improvement concerning to pain, bleeding and healing ${ }^{6}$.

Despite the entire technological advances and the discovery of new materials, it has not yet been possible to develop the ideal dressing for skin wound treatment. In experimental studies, the lack of standard evaluation criteria has been one of the main factors that has made it difficult to determine the healing agent model. Thus, this study was motivated by the difficulty to vouch the healing efficacy of the Aloe vera extract based on the experimental studies revised, comparing it with the latex derivative product recently introduced in the market. Therefore, this study evaluated and compared the treatment of skin wounds in rats under contamination by Aloe vera extract (Babosa) and latex derived from rubber trees (Hevea brasiliensis) and compared with the use of $0.9 \%$ saline solution.

\section{Methods}

The research protocol was submitted and approved by the Ethical Committee under the protocol number 0011-1.

Twenty one Wistar rats, with body weight between 200 and 300 grams, were used. The animals were randomly divided into 3 groups: GL, latex derived from rubber trees (Hevea brasiliensis); GA, Aloe vera extract (Babosa) and GC 0.9\% saline solution, each group initially consisting of 7 animals, which were evaluated at $0,7,14$ and 21 postoperative days.

The rubber tree latex used was in the form of cream-gel obtained from PELE NOVA (Regederm ${ }^{\circledR}$ ) industry and Aloe vera extract to $10 \%$ gel was manipulated by Farmácia Therapeutica (Goiânia-GO), stored in the refrigerator between $2-8^{\circ} \mathrm{C}$ before application on the wound.

\section{Experimental stage}

The rats were intramuscularly anesthetized with ketamine $(70 \mathrm{mg} / \mathrm{kg})$ and xylazine $(10 \mathrm{mg} / \mathrm{kg})$ before the incisions. After the anesthesia was injected, the rats were placed in the prone position, immobilized on acrylic board, submitted to trichotomy of the dorsal region with the blade. A mold was used to demarcate the wounds with an area equivalent to $6 \mathrm{~cm}^{2}(3 \mathrm{~cm} \times 2 \mathrm{~cm})$. An excision of skin fragment and subcutaneous tissue was performed from the marked area to display the aponeurosis. After the procedure, the animals were under observation for 1 hour and it was started the analgesia with nalbuphine hydrochloride $1 \mathrm{mg} / \mathrm{kg} 8$ in 8 hours for 72 hours.

Topical agents of each group were applied immediately, after the surgical wound preparation, in equal amount and enough to cover all lesions once a day during the 21 days experiment. During the daily dressing, the necrotic crust was removed to facilitate the formation of granulation tissue. 
In the attempt to simulate a closer to real external environment, it has not been placed any materials that could set an outer cover to topical agents and prevent the contact of external agents in wounds, as Maravalia that lined the cage and rats excreta, until the cages were cleaned.

\section{Macroscopic evaluation}

The healing process was evaluated through macro and microscopic observation of the injuries on $0,7,14$ and 21 days. At the end of each observation period, the animal was subjected to anesthesia and the injury was photographed using a digital camera Sony Cyber-Shot (8.1 megapixels) set on a fixed tripod $15 \mathrm{~cm}$ from the back of the rats. The images of the induced skin injuries were captured with a size of 640x480 pixels and 24 bits RGB format (Figure 1A). Subsequently, the biopsy of an animal of each group was held in each period in order to maintain sufficient number of animals for statistical analysis of the macroscopic analysis, given the choice of viewing the same animal over time. The removal of 50\% from the incision injury tissue and 50\% from the intact skin was considered for the procedure, with a safety margin of $1 \mathrm{~cm}$ around the wound core and the sample fixed in $10 \%$ formalin ${ }^{7}$. The biopsied rats were euthanized with thiopental intraperitoneally $90 \mathrm{mg} / \mathrm{kg}$ when the sample collection ended, which totaled 9 animals ( 3 animals of each group GC, GL and GA) euthanized during the 21 days of experiment. Animal carcasses were removed and incinerated by a specialized company. The procedures of anesthesia, analgesia and euthanasia were carried out by a veterinary physician.

The photographed wound area of the skin was measured by the software 1.3.1 Image J (NIH, USA) (Figure 1B). To assess the extent of wound area shrinkage, it was used the following formula: Relative Wound Shrinkage $(\%)=$ (Initial injured area - Contracted area) x 100 / Initial injured area ${ }^{8}$. The wound area average and the percentage of shrinkage were calculated using the Excel 2010 software. The analysis of the average measurement variance of wound area on days $0,7,14$ and 21 from the control group, Aloe vera and Hevea brasiliensis was made by Kruskal Wallis test followed by Dunn's multiple comparisons test with significance level of $5 \%(\mathrm{p}<0.05)$. Two Away ANOVA followed by Tukey's multiple comparisons test were done to verify the differences among groups with significance level of $5 \%(p<0.05)$. The D'Agostino \& Pearson omnibus normality test was done previously. It was used the GraphPad Prism 6.00 (GraphPad Software, CA, USA).

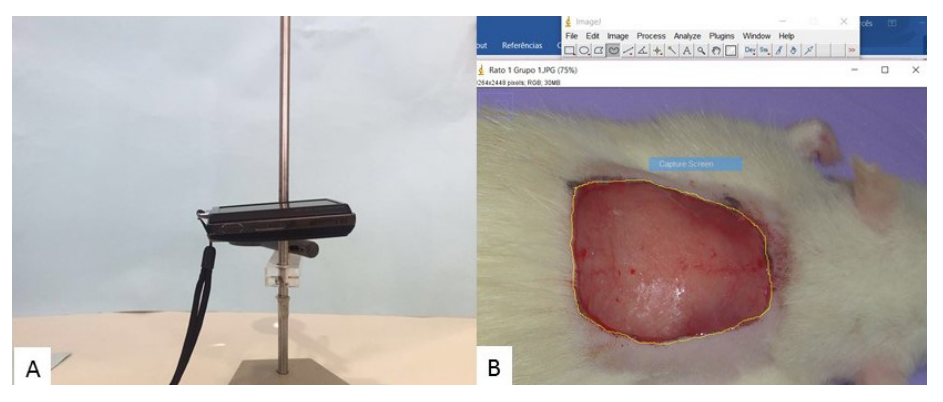

FIGURE 1 - A: Digital camera Sony Cyber-Shot (8.1 megapixels) set on a fixed tripod $15 \mathrm{~cm}$ from the back of mice. B: The photographed wound area of the rat skin was measured by the software 1.3.1 Image J (NIH, USA).

\section{Microscopic assessment}

The samples fixed in $10 \%$ formalin were processed according to histological routine technique, embedded in paraffin and then the produced slides were stained with Hematoxylin and Eosin (HE). The Histological analysis was blindly performed by a single observer under a bright field microscope by $\mathrm{x} 40$, x100 and x200 lenses. The following parameters were observed for the absence (A) and presence $(\mathrm{P})$ : crust formation and reepithelialization; in scores: the type of inflammatory infiltration (polymorphonuclear and mononuclear), fibroplasia, formed cicatricial tissue type (young fibrovascular or organizing), with evaluation of the deep and surface area of the cicatricial formation. The scores were determined as follows: absent (0), mild (1) (1$25 \%$ of the area), moderate (2) (26-50\% of the area), high (3) (51-100\% of the area). To determine the amount of blood vessels it was performed the counting in five random areas of the upper lesion region using $\mathrm{x} 40$ lens, generating a range of number of vessels. The descriptive assessment was performed over the slides and the semi-quantitative was performed between the parameters by analysis of the upper regions of the lesion.

\section{Results}

During the macroscopic evaluation, it was found a larger amount of blackened crust (fibrin-hemorrhagic) on the surface of the wound treated with latex. The groups treated with Aloe vera and $0.9 \%$ saline had less crusting and it looked better and was light yellow (serum). After removing the crust, during the wound assessment, it was found that its edges were irregular over time in animals treated with latex (Figure $2 \mathrm{D}, \mathrm{G}$ and $\mathrm{J}$ ), whereas the animals receiving Aloe vera (Figure $2 \mathrm{E}, \mathrm{H}$ and $\mathrm{L}$ ) and $0.9 \%$ saline solution (Figure $2 \mathrm{~F}$, I and $\mathrm{M}$ ) presented edges retracting regularly. At 21 days, it was found that the latex group had a small central region of an intense red color, apparently exposing the dermal 
region (Figure 2J) whereas the wounds of other treatments were totally rosy and the surface was homogeneous without signs of dermal region exposure (Figure 2 L-M).

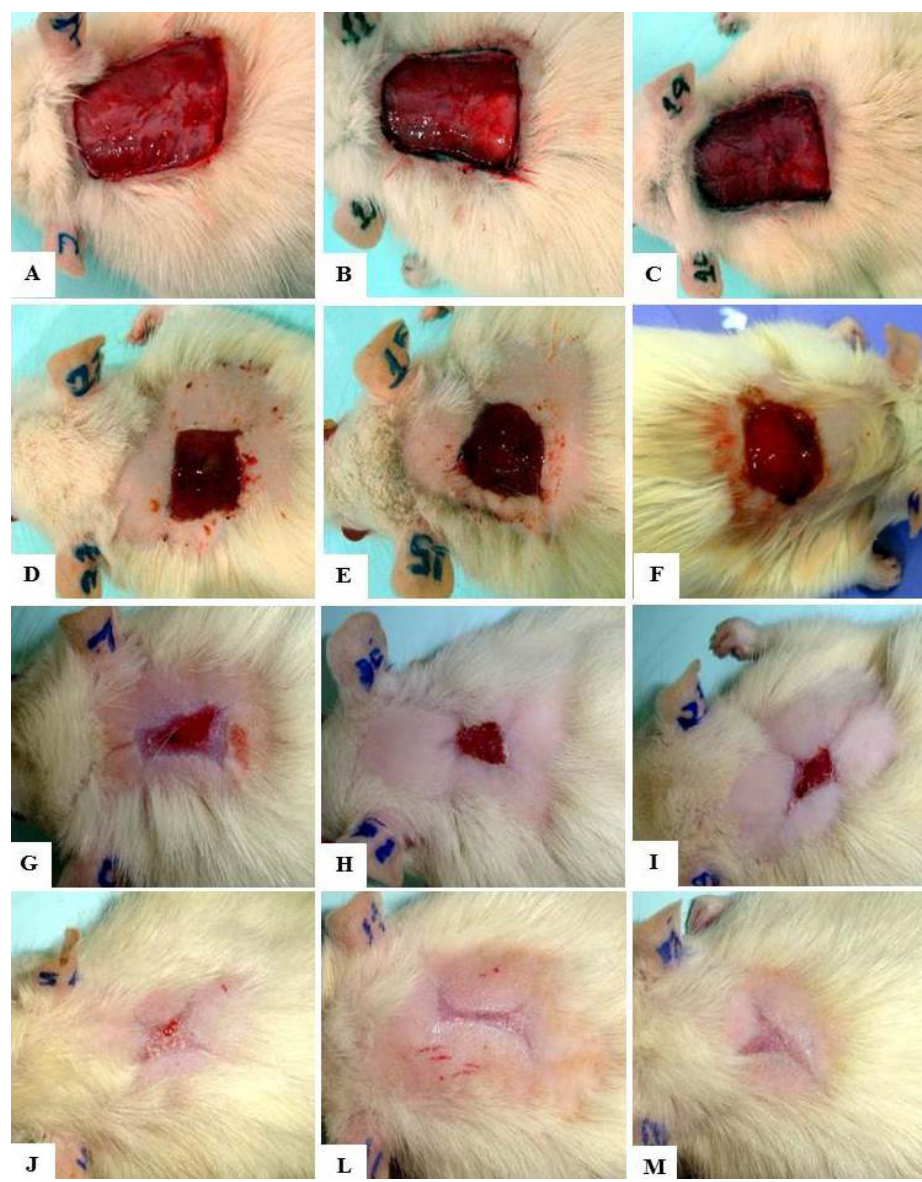

FIGURE 2 - Macroscopic appearance of rat skin wound. A: GL, $1^{\text {st }}$ day. B: GA, $1^{\text {st }}$ day. $\mathbf{C}: \mathrm{GC}, 1^{\text {st }}$ day. D: GL, $7^{\text {th }}$ day. E: GA, $7^{\text {th }}$ day. F: GC, $7^{\text {th }}$ day. G: GL, $14^{\text {th }}$ day. H: GA, $14^{\text {th }}$ day. I: GC, $14^{\text {th }}$ day. $\mathbf{J}: \mathrm{GL}, 21^{\text {th }}$ day. $\mathbf{L}$ : GA, $21^{\text {th }}$ day. M: GC, $21^{\text {th }}$ day.

The average perceptual reduction of the wound area in the three groups in different times is presented in Table 1.

TABLE 1 - Wound reduction average percentage from the animals treated with latex derivative, Aloe vera and $0.9 \%$ saline at $0,7,14$ e 21 assessment days.

\begin{tabular}{ccccc}
\hline Days (n) & $0(\mathrm{n}=7)$ & $7(\mathrm{n}=7)$ & $14(\mathrm{n}=6)$ & $21(\mathrm{n}=4)$ \\
\hline GL & & & & \\
$\begin{array}{c}\text { Wound reduction (\%) } \\
\text { GA }\end{array}$ & 100 & 25.53 & 86.14 & 98.93 \\
$\begin{array}{c}\text { Wound reduction (\%) } \\
\text { GC }\end{array}$ & 100 & 34.62 & 91.43 & 99.57 \\
$\begin{array}{c}\text { Wound reduction (\%) } \\
\text { Goun }\end{array}$ & 100 & 57.66 & 93.53 & 99.69 \\
\hline
\end{tabular}

The Figure 3 presents a comparison of the average extent of the wounds $\left(\mathrm{cm}^{2}\right)$ at $0,7,14$ and 21 days of each group (tree latex rubber, Aloe vera and control). The compared groups wound sizes were: in GC $(\mathrm{p}=0.0174)$ and GA $(\mathrm{p}=0.0363)$ were significantly lower when compared to GL and, GC and GA ( $\mathrm{p}=0.9556)$ which had no statistical difference of wound size. The size of the GC wound was significantly lower when compared to GL on the $7^{\text {th }}$ day of evaluation $(\mathrm{p}=0.0004)$. On the other days, there was no statistical difference between the measurements of the wounds in two groups.

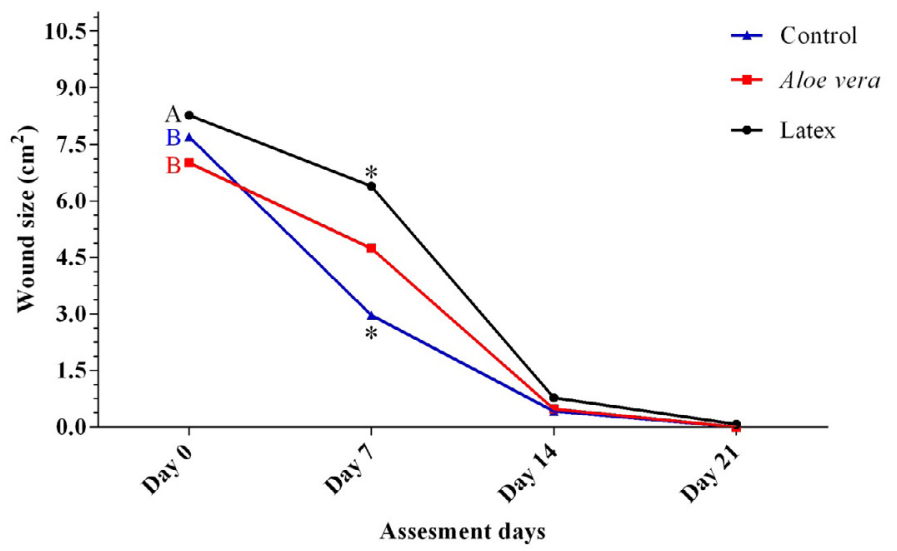

FIGURE 3 - Assessment of the interaction between the three groups of the average wound retraction in $\mathrm{cm}^{2}$ over the assessment days. The groups were compared by Two-Away variance analysis (ANOVA TwoAway) followed by Tukey Test. *represents statistical significance for the interaction of wound size between the groups through the days. A and B represent statistical significance for the interaction of wound size among groups. Significance level: $\mathrm{p}<0.05$.

Figure 4 is the comparative analysis of average areas of the wounds from the three groups in the same periods after using the Kruskal-Wallis test followed by Dunn's multiple comparisons test.

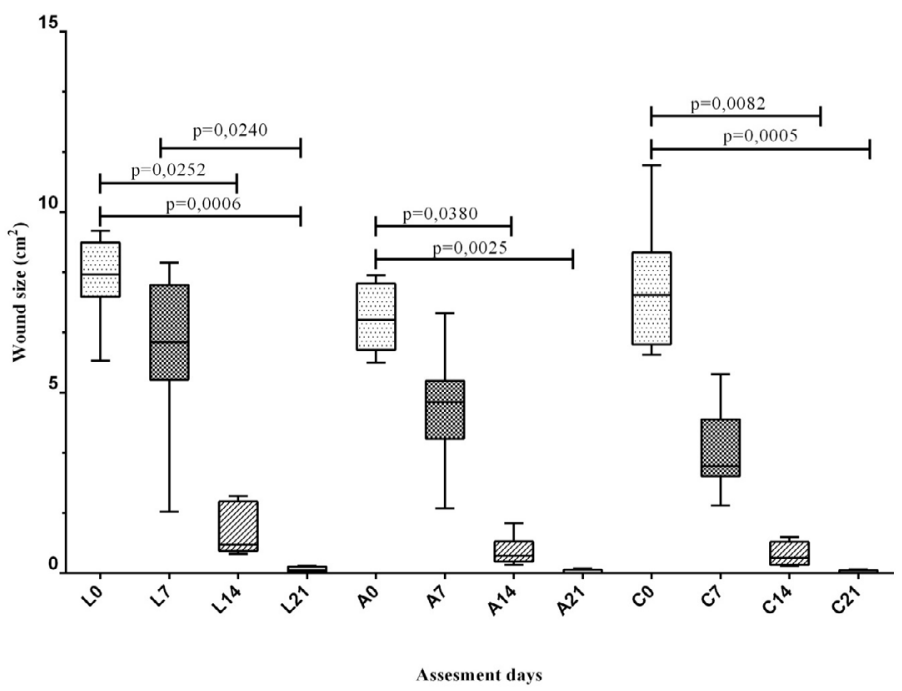

FIGURE 4 - Wound average measurement analysis $\left(\mathrm{cm}^{2}\right)$ in each treatment group (latex derivative $(\mathbf{L})$, Aloe vera $(\mathbf{A})$ and control $(\mathbf{C})$ on 0 , 7, 14 e 21 assessment days. The groups were compared by Kruskal-Wallis test followed by Dunn's multiple comparisons test. Upper line represents statistical significance of wound size regarding to zero time in each group. Significance level: $\mathrm{p}<0.05$. 
On the microscopic evaluation of the injuries at 7 days after incision, it was found on the exposed wounds from the three treatments, absence of re-epithelialization, covered with sharp amorphous eosinophilic materials containing a large amount of cellular debris (crust) and the wound area was large and deep, reaching the muscle region of the skin. On the surface of the lesion just below the crust, there was loads of fibrin and neutrophils. Whereas fibrovascular tissue formed, the upper portion of the lesion presented edema, marked vasodilation and neutrophil infiltration (signs of acute inflammation), and severe neovascularization, presence of mononuclear and young immature fibroblasts and collagen. The deepest region had lower cellularity, more fusiform fibroblasts, evident reducing of acute inflammation signs and the formed collagen presented to be better organized against the surface one. Few differences were observed between the treatment groups at this stage of the assessment.

During the period, in the group treated with latex, an amphophilic, reticulated and refractive material intermingled in the crust was observed, in addition to various bacterial colonies which were also seen in the $0.9 \%$ saline group. The amount of macrophages was marked in the upper region of fibrovascular tissue and more evident than in other groups. The amount of fibroplasia was moderate and counted 35 to 40 new vessels (Table 2), which were well formed. In the deep region, it was found that in this group the formation of fibrovascular tissue was diffusely infiltrating within the muscle and blending with its fibers (Figure 5A).

TABLE 2 - Score by microscopic injuries observed in rat's skin treated with Latex, Aloe vera and $0.9 \%$ saline.

\begin{tabular}{|c|c|c|c|c|c|c|c|c|}
\hline Groups/time & $\begin{array}{c}\text { Injuries } \\
\text { Area }\end{array}$ & $\mathrm{MN}$ & Fibrop & TFVF & TFVD & Re-ep & Crust & $\mathrm{N}^{\circ} \mathrm{NV}$ \\
\hline \multirow[t]{2}{*}{ GL/7d } & Superficial & 3 & 2 & 3 & 0 & A & $\mathrm{P}$ & $35-40$ \\
\hline & Deep & 2 & 2 & 3 & 1 & - & - & - \\
\hline \multirow[t]{2}{*}{$\mathrm{GA} / 7 \mathrm{~d}$} & Superficial & 3 & 2 & 3 & 0 & $\mathrm{~A}$ & $\mathrm{P}$ & $14-20$ \\
\hline & Deep & 2 & 2 & 3 & 1 & - & - & - \\
\hline \multirow[t]{2}{*}{$\mathrm{GC} / 7 \mathrm{~d}$} & Superficial & 3 & 2 & 3 & 0 & $\mathrm{~A}$ & $\mathrm{P}$ & $18-23$ \\
\hline & Deep & 2 & 2 & 3 & 1 & - & - & - \\
\hline \multirow[t]{2}{*}{$\mathrm{GL} / 14 \mathrm{~d}$} & Superficial & 3 & 3 & 3 & 0 & $\mathrm{~A}$ & $\mathrm{P}$ & $21-29$ \\
\hline & Deep & 2 & 2 & 2 & 1 & - & - & - \\
\hline \multirow[t]{2}{*}{$\mathrm{GA} / 14 \mathrm{~d}$} & Superficial & 2 & 2 & 2 & 1 & A & $\mathrm{A}$ & $14-16$ \\
\hline & Deep & 1 & 2 & 2 & 1 & - & - & - \\
\hline \multirow[t]{2}{*}{$\mathrm{GC} / 14 \mathrm{~d}$} & Superficial & 2 & 2 & 2 & 1 & A & A & $19-23$ \\
\hline & Deep & 1 & 2 & 2 & 1 & - & - & - \\
\hline \multirow[t]{2}{*}{$\mathrm{GL} / 21 \mathrm{~d}$} & Superficial & 3 & 3 & 2 & 1 & & & $26-30$ \\
\hline & Deep & 2 & 2 & 2 & 1 & - & - & - \\
\hline \multirow[t]{2}{*}{$\mathrm{GA} / 21 \mathrm{~d}$} & Superficial & 1 & 2 & 1 & 3 & & & $7-10$ \\
\hline & Deep & 1 & 2 & 1 & 3 & - & - & - \\
\hline \multirow[t]{2}{*}{$\mathrm{GC} / 21 \mathrm{~d}$} & Superficial & 1 & 2 & 1 & 3 & & & $24-27$ \\
\hline & Deep & 1 & 2 & 1 & 3 & - & - & - \\
\hline
\end{tabular}

MN: mononuclear cells; Fibrop: fibroplast; TFVF: fibrovascular flaccid tissue; TFVD: fibrovascular dense tissue; Re-ep: Re-epithelialization; $\mathrm{N}^{\circ} \mathrm{NV}$ : neovascularization number. Scores: $0=$ absent; $1=$ discrete; $2=$ moderate; $3=$ accentuated.

The Aloe vera treatment from 7 days presented less evidence of macrophages, fibroblasts and vascular formation in the deep region when compared to the group treated with latex and counted 14 to 20 neoformed vessels (Table 2). In this group, there were no bacterial colonies in the crust. The saline group $0.9 \%$ had 18 to 23 newly formed vessels and the deep region presented more cell formation, the fibroblasts were younger (large oval nucleus), the collagen fibers were more disorganized and slightly loose, besides there was a greater amount of vessels when compared to the other two groups. In both groups, Aloe vera and $0.9 \%$ saline, the fibrovascular tissue did not deeply invade the muscle layer. At 14 days, it was observed that the wound of the group 
treated with latex was wide and deep, with slight retraction appearance comparing to 7 days. There was still crusting and accentuated fibrin on the surface containing bacterial colonies and the dermal region was still widely exposed, despite having early epithelialization in wound edges at the time. In the exposed surface region of fibrovascular tissue, there was a marked quantity of neutrophils, edema and moderate vascular dilatation, and larger quantities of mononuclear and fibroblasts. In the surface region below the marked acute inflammation area, the number of vessels was 21-29. It was found intermingled in fibrovascular tissue amorphous, refractive and amphophilic material surrounded by giant cells (latex?). In the deep region there was increased cellularity and vascularity compared to 7 days (Figure 5B and C).

In this period the Aloe vera group injury area was large, but less deep with moderate reduction compared to 7 days. The reepithelialization was almost entirely present with small exposed area. In this region, the amount of polymorphonuclear was slight and had excellent vascularization. The amount of new vessels below the skin was 14-16 and acute inflammation signs were absent (Table 2). The fibrovascular tissue surface had become more flaccid compared to the deep region, which had fewer blood vessels and more mature cells (spindle). In the use of $0.9 \%$ saline, regarding to Aloe vera, the area of granulation tissue formation was smaller and there was re-epithelialization, but with greater exposed area. On the surface there were few signs of acute inflammation. The formed vessels are long, dilated and well-targeted to the surface from the deep scar region. There was more cellularity (moderate) on the surface regarding to the deep zone, in which collagen was more organized and the fibroblasts were more mature (Figure 5D).

At day 21 of treatment, it was found that the lesion in the three groups had been completely re-epithelized. Treatment with Aloe vera generated the formation of an organized epithelium with basal membrane, basal cell and subsequent layers aligned with richly vascularized subepidermal region (Figure 5G) while the saline group and $0.9 \%$ latex presented a disorganized region with some acanthosis outbreaks, larger amount of discretely balloon cells and areas of projection to the dermis (Figure 5E, F and $\mathrm{H}$ ). The scar of the $0.9 \%$ saline group and Aloe vera was small and well retracted. There was no cellularity difference between the superficial and deep regions and it could be observed a discrete amount of macrophages and moderate amount of fibroblasts.

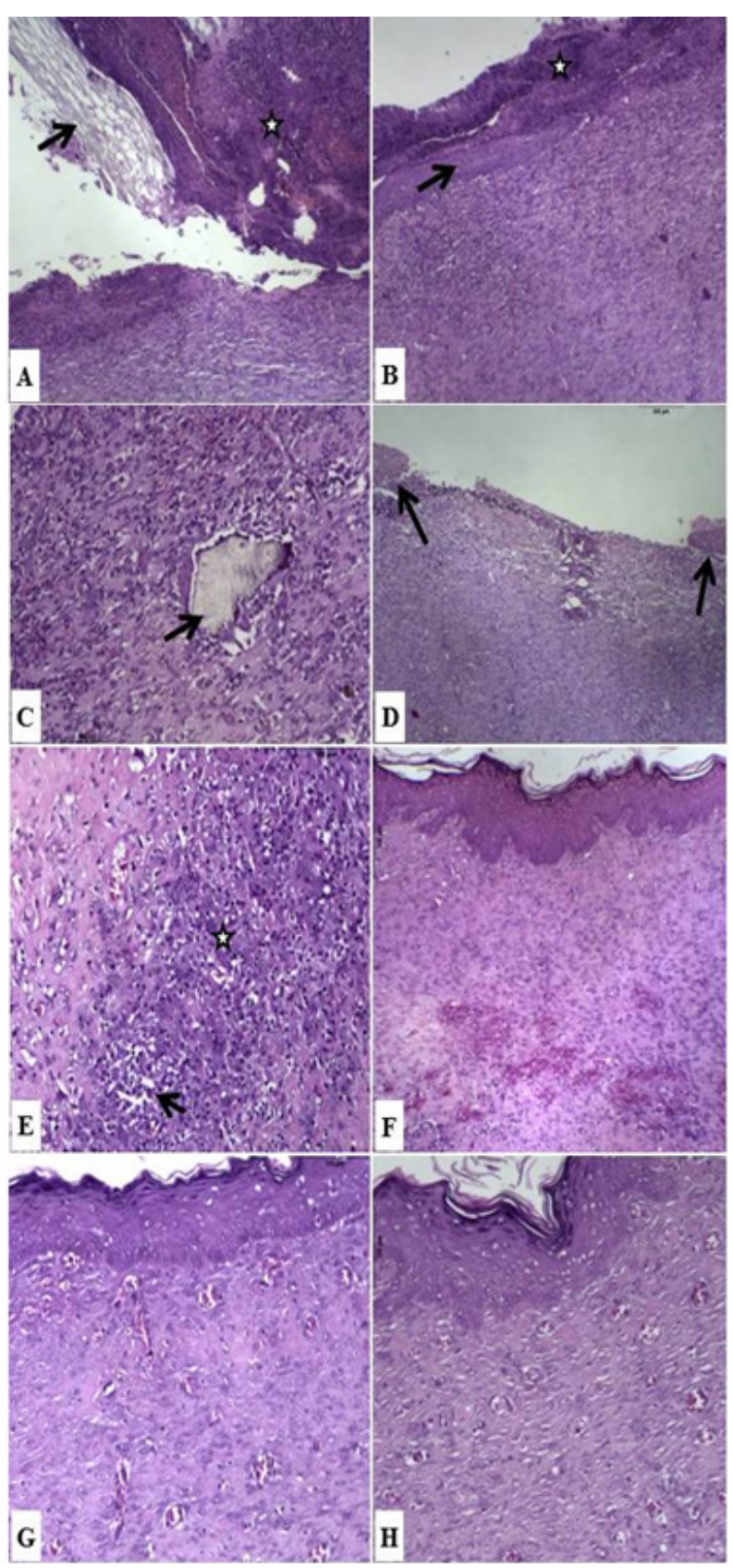

FIGURE 5 - Photomicrographs of skin wound in rats, HE. A: GL, $7^{\text {th }}$ day, $\mathrm{x} 4$. Accentuated crusting (star) on the surface of fibrovascular tissue, associated with the cross-linked amphophilic refractive - latex material (arrow). B: GL, 14 ${ }^{\text {th }}$ day, $x 4$. Edge re-epithelialization (arrow), fibrin layer and the surface crust (star). C: GL, $14^{\text {th }}$ day 14 , x10. amphophilic refractive material surrounded by giant cells (arrow). D: GA, $14^{\text {th }}$ day, $x 4$. Almost complete re-epithelialization of the edges (arrows) with reduced exposed area. E: GL, $21^{\text {th }}$ day, x10. Macrophages containing basophilic material, and forming syncytia (star) with necrotic area (arrow). F: GL, $21^{\text {th }}$ day, $x 4$. Re-epithelized surface and surface area suffered marked cellularity. G: GA, $21^{\text {th }}$ day, x10x. Organized and linear re-epithelialization, vascularization and subepidermal surface fibrovascular tissue presenting low cellularity and organized collagen (tending to maturity). $\mathbf{H}$ : GC $21^{\text {th }}$ day, $\mathrm{x} 10$. Epithelialization with areas of dermal projections, evident balloon cells, surface area presenting low cellularity, and slightly flaccid collagen. 
The Aloe vera group had little vascularization (7-10 vessels), wide and well-formed vessels and collagen was well organized and the $0.9 \%$ saline group had higher amount (24-27), mainly capillaries and collagen was slightly more flaccid than the Aloe vera group. In contrast, in the latex group, the scar area was wide and had high cellularity, mainly macrophages, which formed multifocal groups. These cells were replete with slightly basophilic material and sometimes formed syncytia and necrotic area. The number of vessels was from 26 to 30 formations (Table 2). The results of the semi-quantitative assessment are in Table 2.

The microscopic results indicate that Aloe vera at 21 days generated better proliferation, epidermal and collagen organization compared to the $0.9 \%$ saline group. However, both were effective towards the scar formation with a reduction to 14 days of acute inflammation and decrease of macrophages and blood vessels at 21 days, indicating scar maturation. The group treated with latex maintained acute inflammation at 14 days. Moreover, the progression to active chronic at 21 days with marked infiltration of macrophages evolving to microgranulomas, which exacerbated and slowed the healing process due to the large amount of macrophages, increased area of fibrovascular tissue, less organized collagen maturity, high amount of newly formed immature blood vessels maintenance and fibroblasts immature characteristic.

\section{Discussion}

In this study, a gradual and significant reduction of injury was observed at $7^{\text {th }}$ and $14^{\text {th }}$ day corroborating the fact that the healing process occurs in a centripetal way reducing the area exposed by the local reepithelialization stimulus 9 . In addition, comparing wound among groups Aloe vera and $0.9 \%$ saline solution promote significantly better effect to wound healing regarding to the use of tree latex rubber.

The surface of the wound treated with latex had a higher exudate, with formation of a blackened crust (fibrin-hemorrhagic). In the groups treated with Aloe vera and $0.9 \%$ saline the exudation was noticeably smaller and the product was light yellow (serum). This finding indicates that the surface damage caused by the use of latex urged a greater inflammatory reaction and local exudation. Moreover, the edges of the wound irregularly retracted when compared to the regular produced in the Aloe vera and $0.9 \%$ saline groups.

The groups treated with Aloe vera and $0.9 \%$ saline solution presented the expected evolution of the healing process, with a slight better epidermal and collagen organization. Since the phases of normal tissue repair match increase in macrophages within the first 72 hours, maximum vascularization around the 5 th day, followed by formation of granulation tissue and reduction of mononuclear; and around the second week ripening signs of scar fibroblasts and collagen increase with a decrease of inflammatory cells ${ }^{9}$. While the latex group presented no reduction in the number of macrophages and blood vessels from day 14 as expected from these injuries. Thus, there was an exacerbation of the inflammatory and cicatricial process in this group, with formation of microgranuloma.

The granuloma foreign body wrapped in refractive amphophilic material observed on day 14, the accumulation of macrophages containing basophilic material and forming syncytia on day 21 on the group treated with latex derivative raises hypothesis over the biological incompatibility of this product. This result is contrary to former ones seen in some studies ${ }^{2,10}$ indicating the latex membrane as an excellent biocompatibility agent. However, this study suggests low compatibility of latex as a curative agent for skin wounds in rats, corroborating a perineal herniorrhaphy experiment in dogs, in which there was biomembrane extruding after the formation of a local granulomatous inflammatory process.

Angiogenesis was higher in the latex group in all time periods, which was also found in the previously refered studies. These suggest that the intense vascularization happens due to the large number of macrophages in all time periods, which secrete angiogenic factors such as TGF- $\beta$, TGF-1, PDGF. However, these cells induce local injuries when they are in large activity due to high production of oxygen reactive species ${ }^{9,10}$. Based on this information, it is suggested that the latex delays the healing process due to exacerbated demand of these cells which induce continuous local injury. This hypothesis comes from the observed in the descriptive microscopic evaluation, which presented the formation of broad and deep fibrovascular tissue (reaching beyond the muscle region of the skin), high cellularity maintenance at 21 days, immature fibroblasts and surface and deep collagen when compared to the other two groups. Thus, latex appeared to be in the inflammatory phase while the other groups were in the maturation and organization phase.

Both the $0.9 \%$ saline and the Aloe vera extract results presented as being temporarily satisfactory regarding to the stages of healing, since that there was angiogenesis and inflammatory cells prevalence initially, with subsequent increase of fibroblasts, flaccid to dense connective tissue organization, reduction of vascularization and complete re-epithelialization'. However, even though the data were not sufficient, the Aloe vera group appeared to have generated better tissue organization over time. It was this group which had the most organized epidermis with basal membrane and aligned basal cells (palisade), rare cells with 
immature appearance, cell extracts were well structured, there was a satisfactory subepidermic vascularization which was not observed in the other groups and the collagen was more organized and eosinophilic. Moreover, the reduction of macrophages and vascular regression was marked out of 14 (14-16 vessels) to 21 (710 vessels) days, which is a scar maturation characteristic ${ }^{9}$. It was still verified that re-epithelialization at 14 days was already almost complete. Thus, it suggests the performance of mannose-6-fosfate as a substrate for fibroblasts and, therefore, for collagen organized structuring and wound contracture. It was also observed in rat wounds and burns ${ }^{3}$. In addition, it was not detected any bacterial colony in the crust at 7 days in this group, which may infer the antibacterial and antifungal activity of anthraquinones present in this extract ${ }^{5}$.

The saline group also presented efficient scar formation, promoting initial retraction of the wound from the 7 days. This study presented that in conditions where it is not possible to employ an adjuvant factor in healing, due to financial or operational nature, cleaning the wound with $0.9 \%$ saline solution ensures adequate healing process with re-epithelialization and absence of secondary contamination at 21 days.

This analysis arose the need for further studies regarding the use of the latex derivative and Aloe vera extract in the wound healing process, particularly regarding to the biocompatibility of products in different regions and injuries.

\section{Conclusions}

In the statistical comparison of the average wound size, the statistical difference observed over 7 days of the experiment was not maintained throughout the experiment, which has not allowed for the evaluation of which is the best topical agent regarding that aspect. As for the visible appearance of the scars, the Aloe vera and control groups showed less crust and regular edges in detriment of the latex. The higher angiogenic potential of latex was microscopically confirmed against other products and there was a better healing process temporally distributed in phases in the Aloe vera group. This study resulted in questioning the healing process delay in the group treated with latex derivative and if it would be related to the foreign body granuloma formation.

\section{References}

1. Franco D, Gonçalves LF. Feridas cutâneas: a escolha do curativo adequado. Rev Col Bras Cir. 2008;35(3):203-16. doi: 10.1590/ S0100-69912008000300013.

2. Brandão ML, Coutinho Netto J, Thomazini JA, Lachat JJ, Muglia
VF, Eli Piccinato C. Prótese vascular derivada do látex. J Vasc Bras. 2007;6(2):130-41. doi: 10.1590/S1677-54492007000200007.

3. Araujo MM, Massuda ET, Hyppolito MA. Anatomical and functional evaluation of tympanoplasty using a transitory natural latex biomembrane implant from the rubber tree Hevea brasiliensis. Acta Cir Bras. 2012;27(8):566-71. PMID: 22850709.

4. Tarameshloo M, Norouzian M, Zarein-Dolab S, Dadpay M, Mohsenifar J, Gazor R. Aloe vera gel and thyroid hormone cream may improve wound healing in Wistar rats. Anat Cell Biol. 2012;45(3):170-7. PMID: 23094205.

5. Oliveira SHS, Soares MJGO, Rocha PS. Uso de cobertura com colágeno e aloe vera no tratamento de ferida isquêmica: estudo de caso. Rev Esc Enferm USP. 2010;44(2):344-9. doi: 10.1590/S008062342010000200015.

6. Rahmani N, Khademloo M, Vosoughi K, Assadpour S. Effects of Aloe vera cream on chronic anal fissure pain, wound healing and hemorrhaging upon defection: a prospective double blind clinical trial. Eur Rev Med Pharmacol Sci. 2014;18(7):1078-84. PMID: 24763890.

7. Mendes Júnior ECS, Fausto V, Rosa SC. Análise histológica e morfométrica da área cruenta tratada com membrana de silicone: estudos em ratos. Rev Assoc Med Bras. 2007;53(5):395-400. doi: 10.1590/S0104-42302007000500014.

8. Al-Watban FA, Andres BL. Polychromatic LED therapy in burn healing of non-diabetic and diabect rats. J Clin Laser Med Surg. 2003;21(5):249-58. PMID: 14651792.

9. Hosgood G. Stages of wound healing and their clinical relevance. Vet Clin North Am Small Anim Pract. 2006;36(4):667-85. PMID: 16787782.

10. Frade MAC, Coutinho Netto J, Gomes FG, Mazzucato EL, Andrade TAM, Foss NT. Curativo de biomembrana vegetal e hipersensibilidade. An Bras Dermatol. 2011;86(5):885-91. doi: 10.1590/ S0365-05922011000500004

\section{Acknowledgement}

To Dra. Mara Rubia Nunes Celes, General Pathology Professor of the IPTSP/UFG for contributing with the statistical analysis developed along with this research.

\section{Correspondence:}

Marcelo Luiz Brandão

Escola de Ciências Médicas, Farmacêuticas e Biomédicas

Pontifícia Universidade Católica de Goiás

Avenida Universitária, 1.440

74605-010 Goiânia - Goiás Brasil

Tel.: (55 62) 3946-1486

marceloluizbrandao@gmail.com

Received: May 18, 2016

Review: July 20, 2016

Accepted: Aug 21, 2016

Conflict of interest: none

Financial source: none

${ }^{1}$ Research performed at Laboratory of Surgical Technique, School of Medical Sciences, Pharmaceutical and Biomedical, Pontificia Universidade Católica de Goiás (PUC-Goiás), Goiania-GO, Brazil. 